\title{
The Marital Balance of Power and Quid Pro Quo: An Evolutionary Perspective
}

\author{
Kevin B. Kerber
}

Department of Psychiatry, University of Michigan, Ann Arbor

\begin{abstract}
Although the marital therapy literature recognizes the importance of quid pro quo in marital negotiations, there has been little attention to certain important sources of power for men and women in that process. This paper will show how parental investment, certainty of paternity, patterns of mate preference, intrasexual competition, and reproductive status all affect the bargaining positions of men and women. Both premarital and marital negotiations will be discussed. Put into a developmental perspective, this will help clarify what is at stake in the common sources of conflict between the sexes. These considerations form a central part of the socioecology of marriage.
\end{abstract}

KEY WORDS: Parental investment; Marital conflict; Marital therapy; Reproductive strategy; Quid pro quo.

\section{INTRODUCTION}

For both men and women through the centuries, the tribulations of beginning and maintaining an enduring sexual relationship have been sources of anxiety, pleasure, frustration, perplexity, and humor. In our monogamous society, there is an enormous emphasis on marital harmony and stability. Expectations are high, and marital failure may be seen as a result of individual psychopathology, such as immaturity, self-centeredness, dependency, poor communication, and so on. At the very least, individuals are likely to feel guilt and a loss of self-esteem when they fail to have the harmonious relationship "normal" people are supposed to have. The loss of self-esteem will be especially acute when the conflict is public knowledge and, in the extreme, ends in divorce.

Received January 9, 1992; revised September 17, 1994.

Address reprint requests and comespondence to: Kevin B. Kerber, M.D., University of Michigan Department of Psychiatry, 400 E. Eisenhower Parkway, Building 2, Suite A, Ann Arbor, MI 48104. 
With a divorce rate that has risen sharply above historic levels, these experiences have become quite common. The negotiations between husband and wife have been affected by changes in family structure, in particular by the greater educational and occupational independence of women (Glick and Lin 1986; Blumstein and Schwartz 1983). Since the companionate marriage (one based on individual choice and love) has become more frequent during about the same period as the rising divorce rate, it is evidently not a means of avoiding conflict.

Despite long-standing cultural norms about the "proper" sex roles in a Inarriage, psychiatrists and marital therapists have found it useful to analyze marital negotiations in terms of a quid pro quo (Jackson 1965; Fish and Fish 1986). With this concept they try to capture the exchange negotiated in a marriage by the wife and husband. It will also apply to the development of symptoms (such as depression) by one spouse in response to a particular balance of power or change in that balance. Fish and Fish assert that the quid pro quo is the common element to all the systemic theories of marital therapy and that, from this point of view, "the central marital issue is the balance of power."

Unfortunately, although they recognize that three important domains of negotiation have to do with moncy, sex, and in-laws, they attend little to certain influences in these domains. Even a recent "integrative" approach to marital treatment (Polonsky and Nadelson 1985) offers no general observations or theories about the developmental hurdles faced by men and women in these areas.

The concept of quid pro quo encompasses not only conflicts of interest but also the resolution of these conflicts. The reconciliation of individuals after intense conflicts is a long-standing feature of primate evolution (de Waal 1989). Across a variety of primate species, de Waal noted that "The goal of conflict resolution is not peace per se; it is the maintenance of relationships of proven value." In this way, "screaming and shouting followed by tenderness may actually strengthen a bond, in that the sequence assures both parties of the viability of the relationship. We do not trust a ship before it has weathered a storm." He describes convincingly how the negotiation of conflict and conflict resolution draw heavily on important aspects of human affiliative psychology, from the cognitive skills needed to plan and form strategy in complex group interactions, to empathic understanding of the needs and feelings of others, to the emotional rewards of reconciliation.

It has been suggested that these primate developments were advanced further in human evolution by the high degree of economic reciprocity that has characterized the human family (Washburn and Lancaster 1968). The huntingand-gathering way of life required a well-developed division of labor, and, with it, even greater skills for managing conflicts and maintaining relationships.

It will be the goal of this paper to show that a fuller understanding of marital conflict is possible when the differing circumstances and developmen- 
tal challenges of the sexes are considered. This understanding will clarify some importance influences on the marital balance of power and the quid pro quo. This perspective will draw heavily from recent developments in the application of evolutionary theory to human behavior. Nevertheless, I will not assert that evolution has shaped any "essential" male or female character or cognitive tendencies. Instead, I will attempt the more modest undertaking of trying to show how a variety of biological and cultural forces influence the reproductive choices men and women make. Even if it were the case that men and women were cognitively identical, there are still good reasons to expect that they would make different reproductive choices. This argument will proceed from a discussion of parental investment, differences in male and female intrasexual competition and status, and the costs of infidelity and abandonment, to an examination of the consequences of these factors in male/female negotiations throughout life.

\section{PARENTAL INVESTMENT, INTRASEXUAL COMPETITION, AND STATUS}

The concept of reproductive strategy helps to see how the sexes may shape their behavior with each other. Daly and Wilson (1983) write that "a reproductive strategy is a program for the allocation of reproductive effort" and divide this effort into mating effort and parental effort. Since men and women differ in terms of their reproductive potentials and limitations, they will tend to distribute this effort differently and to utilize different strategies, strategies that may often be in conflict with one another (Buss 1989a).

Reproductive strategies are shaped by a variety of biological, ecological, and cultural factors. A fundamental biological effect concerns parental investment where, as described by Trivers (1972), the sexes have an enormous difference in many species. He defines parental investment as "any investment by the parent in an offspring that increases the offspring's chance of surviving (and hence reproductive success) at the cost of the parent's ability to invest in other offspring." For men the minimum parental investment need not necessarily extend beyond the effort of a brief copulation. For women the minimum investment is huge, beginning with the considerable costs of pregnancy, delivery, and nursing. The energetic or metabolic commitment alone is great. In addition, until quite recently, childbirth was a major source of female mortality. A pregnant woman can make no alternative reproductive commitments, whereas a man may fertilize another partner almost immediately.

Examining a variety of species, Trivers showed that, in general, the sex that invests more will be motivated to be choosier in mate selection while the sex that invests less will have to compete for sexual access to them. For most species this means that females will evaluate and select mates carefully. It is especially important in those species where mates are needed to contribute to the continued care of offspring (e.g., human beings). The female will assess the quality and character of the malc to determine if he is reliable and likely to 
make the investment of parental effort that will be most beneficial to her offspring. Since the female is obligated to make a large parental investment, she will have reason to choose a male who will not take advantage of her and depart after copulation without further contribution.

'The decision whether to invest or desert is a complex one for both men and women, but the dilemma is slightly different for the sexes. As pointed out by Dawkins and Carlisle (1976), before deserting the family, each individual should weigh the chance of finding another mate and the cost and likelihood of raising another child to the level of development (and investment) of the current offspring. Past investment matters only to the extent that it reduces the need for future investment. It doesn't matter who provided the past investment. However, because of lengthy human gestation and lactation, the male has the first opportunity to desert. This makes "female desertion unlikely to be an ESS" (evolutionarily stable strategy) (Maynard Smith 1977). In many families, extensive paternal investment will greatly improve the survival and later success of offspring, and fathers will therefore be motivated to stay. Even where this is true, however, when a point is reached where additional paternal investment makes little difference to offspring success, the male still finds it easier to desert than the mother. This has to do with the ease of finding a mate. A woman's physical attractiveness is likely to decline with age. As will be discussed later, a man's reproductive appeal may increase with age and, since men often marry women younger than themselves, they have a larger pool of potential mates from which to choose. Hill and Low (1992) have shown how the fewer remaining reproductive opportunities for older women influence their willingness to "desert" current reproductive opportunities, that is, have an abortion.

Internal fertilization and gestation have another important consequence. While women are certain of maternity, men can never be entirely certain of paternity. For a species like ours, where children may receive a very large investment for many years, men run the risk of investing heavily in a child they did not father. Claustration and infibulation of women, as well as a variety of other practices, are used to improve certainty of paternity in many human groups (Daly and Wilson 1983). A widespread double standard exists for the sexes where female sexual freedom is greatly restricted compared to males (Betzig 1989). Male sexual jealousy and asymmetrical adultery laws relate to cultural rules around the world where a wife's adultery is a crime and her husband is the victim (Daly et al 1982). The male adulterer's marital status is often irrelevant to his punishment.

Patterns of investment are influenced by various social and ecological factors. The avunculate exists in some nonindustrial societies where there is low certainty of paternity; men therefore invest more than they would otherwise in their sister's offspring (with whom they are more certain of a genetic relationship) (Alexander 1979; Flinn and Low 1986). Ecological features such as the distribution and predictability of resources will affect mating patterns and competition (Emlen and Oring 1977; Rubenstein and Wrangham 1986; 
Foley and Lee 1989). In societies operating at or near subsistence level, it will be difficult for very many men to achieve sufficient wealth to afford more than one wife. As a society becomes wealthier, more complex, and stratified, a greater number of men will have the means to afford multiple wives (Betzig 1982).

A large majority of human societies around the world permit men to have more than one wife (Daly and Wilson 1983). Even in societies where it is permitted, though, most men have only one wife, polygamy being reserved for the most affluent men. When combined with the tendency for men to marry women younger than themselves, this polygamy means that some men-especially younger, less affluent and less established men-may be unable to obtain a wife at all. This is similar to what exists in many species where there is greater female investment and where resources permit some males to obtain more mates than other males; there is greater variability in reproductive success among males than among females. This may be less true today of societies that have passed through the demographic transition and have socially imposed monogamy. Nevertheless, it remains true that men are both more likely to remain single and to remarry than women (Daly and Wilson 1983). Data from 1960 showed that of men in the lowest fifth of income, 30\% were single; among men whose earnings placed them in the top fifth, only $5 \%$ were single (Trivers 1985).

This means that the consequences of success and failure are more extreme for men than for women. As in other species, the larger size of males and their higher mortality from internal and external causes reflects this steeper competitive hierarchy (Wilson and Daly 1985). Part of this is the greater male propensity for risk-taking and for fights-even to death-over conflict that involves the relative status of the two individuals (Wilson and Daly). Such fights will likely be more common among men lower in status and who are fearful of any encounter that may drop them further, especially if the contest and the risk of defeat and humiliation are publicly observed. Since there will be fewer ecological settings where differences in status between two women will result in a difference in reproductive success sufficient to justify risking death, such violence will be rare among women.

\section{DYNAMICS OF NEGOTIATION THROUGH ADULTHOOD}

\section{Premarital Negotiations}

Negotiations between the sexes in adolescence or early adulthood are complicaled by a number of factors. Both sexes are likely to be inexperienced in managing the vulnerability and give and take of early courtship. But they aren't just uncertain about the procedures of the process; they also are likely to have an imperfect understanding of the value of what they are trading. This seems especially likely to be a problem for a young woman, both because of dilemmas posed by her sexuality and because of the discrepancy between the 
great value of her sexuality, her developmental immaturity, and her frequent perception of her own lower status. These difficulties are a part-but only part-of the reason why, in so many cultures, parents try to control who their children marry.

To understand these problems, one must perceive, as pointed out by Symons (1979), that women control the ultimate sexual resource, that is, access to their reproductive futures (with all the obligation of maternal investment mentioned earlier). He described the situation by saying that sex is a service women grant to men of their choosing. A young woman, with her whole reproductive life ahead of her, controls this extremely valuable resource. In many cultures, families go to great lengths to guard and protect this resource and encourage the daughter to be sexually restrained. This will especially be the case in cultures where fathers make significant investment in offspring and therefore demand high degrees of certainty of paternity.

Despite the power that this control would seem to grant to young women, many of them have difficulty wielding it effectively in their negotiations. If a woman comes from a family where women have little power or sons are valued more, she may perceive herself to have relatively low status. Even if she is attractive and intelligent, she may strike a poor bargain in choosing a mate, underselling her true value. Psychopathology may often play a role here, as neurosis or very low self-esteem causes inhibition and failure to develop or utilize personal strengths interpersonally (compare Johnson 1976). One wonders whether some fathers use derogation of daughters as a way of controlling their sexuality and autonomy. They may use the same tactic with sons but, since sons do not become pregnant, perhaps without the same concern over control of specifically sexual behavior.

Buss $(1987,1989 \mathrm{~b})$ has collected a variety of evidence to support what has been the pretheoretical observation of many; namely, that wealth and high status will have a greater effect on male attractiveness and that physical attractiveness will have a greater effect for females. Consistent with this is Elder's (1969) data that physical attractiveness was most predictive of a woman's ability to marry a man of higher occupational status. This was especially marked for women of lower social class origins. In effect, such a marriage is an exchange between the status a woman possesses by virtue of her beauty and the greater socioeconomic status of the man. In such negotiations, though, the man is likely to be somewhat older, giving him something of an advantage in experience and economic control.

Even such higher status males will have to be appropriately deferential if they wish to gain sexual access. If a woman can use the power she has by virtue of her status - whatever its origin - then she is in a position to define the conditions under which she will offer that access. There is evidence that it is the woman's attitude that is "usually the major restraining force" on whether a couple has intercourse (Peplau et al 1977). Regarding religious backgrounds and traditionalism, those same authors wrote that "characteristics of the woman were better predictions of whether a couple had coitus than character- 
istics of the man." Given her greater minimum parental investment, a woman is likely to demand evidence not only of emotional commitment to her but also the ability (i.e., wealth) and willingness to invest in her and any offspring. This is present in familiar courtship behaviors (e.g., gift giving, deferential chivalrous behavior) by which males seek to impress females and ingratiate themselves to them (Buss 1988).

Reproductive status is determined by both the quality and range of alternative potential mates. Most women, especially attractive ones, know a large number of men who would be quite willing to have intercourse with them. The problem is in finding a man of sufficiently high status who is really willing to make a commitment to her.

For men, the situation is quite different. Young men without wealth or occupational status may find no one willing to engage sexually with them. To be seen as sexually desirable by women, they may need to compete successfully with other men in some arena. This relates, again, to the steeper male status hierarchy and young men's willingness to engage in more extreme or dangerous behavior in order to rise in status over others (Wilson and Daly 1985).

Only men of relatively higher status will have the range of potential sexual partners that many women will have. Unlike the situation for women, there will be relatively few men of such high status that they have large numbers of potential partners to whom they may do the "favor" of granting sexual access. Only a few of the most visible and successful male athletes, musicians, and actors will have such a range of choices (e.g., with women seeking such sexual favors known as "groupies"). There will be many more women in such a position of higher desirability. This is an important part of many young women's higher reproductive status and power. This difference seems to be preserved among those of lowest status as well. ${ }^{1}$

\section{Marital Negotiations}

While many of the above considerations continue to play a role after a couple has married, there are important changes. Recall that much male deference was a response to female control over sexual access. After marriage, while a man retains his occupational status and, often, economic control, a woman will probably have a harder time withholding sexual access. He may become less deferential and more assertive in deciding where money is to be spent, money that is often earned largely by him. (Even in our society, men continue to earn more than women, even for similar work.) There may be conflict over whether money will be spent to enhance his status and goals or hers.

Given the husband's desire for certainty of paternity, he may feel threatened by expenditures that do too much to enhance the wife's attractiveness and

\footnotetext{
'Anecdotally, when I used to consult at a community mental health center with the chronically mentally ill, the women-even the least attractive ones-still had to deal with unwanted sexual advances. By contrast, the least attractive men seemed to have almost no sexual opportunities.
} 
status. Toward this same end, he may also try to limit the wife's social freedom and autonomy. In some cultures this is perfectly acceptable. Many Muslims, for example, require that women cover their faces and bodies almost completely. In a culture like ours, however, this sort of strategy seems likely to be used only by men who, for whatever reasons, are very uncertain of their ability to retain a faithful wife. In fact, among upper class or upwardly ambitious men, there may be considerable effort to enhance the attractiveness of their wives, whose beauty is widely seen to be a mark of the man's high social and reproductive status.

Decisions about when to have the first child present a variety of difficulties. Of course, given that--even today-birth control is less than perfect, this step is often not taken planfully. Nevertheless, it is common to defer this step until the resources of the couple are sufficient to successfully rear the child. If there is significant marital conflict or if the husband appears uncertain to invest appropriately, the wife may wish to postpone childbirth until the future of the relationship is more clear. She may feel that having a child will make it more difficult for her to leave the husband should the marriage become unsatisfactory. But the husband may be quite aware of that and insist all the more strongly. The couple may try to cement an unstable marriage by having children. This attempt to create a common cause for the parents is very risky, because it involves a large investment by the wife in an uncertain situation and at the same time limits her negotiating power by making it more difficult for her to withdraw from the relationship.

Once they have become parents, both individuals will want to ensure that the partner does, in fact, contribute as promised. Since the mother has already invested heavily, her best strategy is to try to extract greater contributions from her husband. This has at least two purposes. Each increment of investment from him will both increase the cost of desertion for him and tend to reassure her that he is intending to stay. Such contributions may also increase her reproductive success, perhaps by enhancing the health or survival of the child.

Such matters are common sources of marital conflict. When there is an extensive division of labor, it becomes very difficult to arrive at an equitable distribution of effort. Both individuals will struggle to establish a high value for their own contributions while seeking, perhaps, to attribute a lower value to thcir spousc's. Each tries to get the other to do more. This will be especially important for the woman, whose investment is not only larger, but also more difficult to limit. She may seek to evoke guilt in the male by calling up societal standards of commitment and contribution.

Even if both individuals are making significant contributions, those of the mother tend to be more directly bestowed upon the child and are likely to involve the satisfaction of basic needs (food preparation, personal hygiene, clothing, etc.) that are unavoidable and therefore less under her discretionary control. Men tend to contribute indirectly by working outside the home for money. In this way they have greater discretionary control over their actual contribution to the offspring. That men tend to control the economic resources 
of the family not only gives them more power within that unit but also gives them the opportunity to invest elsewhere. Women have quite understandably tried to gain greater control over economic resources by also working outside the home. This has permitted them to a greater degree of independence and a range of opportunities. However, as many mothers working outside the home have discovered, this also increases further the size of their investment. Since male contributions at home may increase little if at all when the mother takes a job (Blumstein and Schwartz 1983), the discrepancy between their contributions may only become greater, adding to the dilemma in which the mother finds herself (compare Hill and Hill 1990).

Once she has a child, her options become more limited. Whether or not she has any special maternal feelings, a mother stands to lose more-because of her greater initial investment-if she were to leave the family. (This is consistent with Dawkins and Carlisle (1976); after all, given her large minimum investment in future offspring, future prospects must be very good relative to current prospects to make desertion worthwhile. In other words, it is likely to be cheaper and easier for a man to replace current offspring.) The more children she has, the more marked this discrepancy. Her reproductive status also drops because, with children, her reproductive value to other men drops. (There is disagreement on this point; compare Stewart et al. 1985 with Glick and Lin 1986.) Other men may be understandably reluctant to enter into a relationship where they may have to make significant contributions to children of another father and where the woman has already committed a large part of her parental effort. If she remains married, as long as she is raising her husband's children and planning continued maternal investment, she retains considerable reproductive value to him. After the children leave home, however, her reproductive value decreases considerably. Although she may still be able to invest in her children in a variety of ways, she may have less leverage with her husband. For all these reasons, as well as a likely decline in physical attractiveness, a woman's number of alternative mating opportunities is very likely to decrease with age, the drop becoming more marked after about 45 years.

A man's reproductive capabilities are not so limited by physical or physiologic changes - he may be capable of having children years later than a same-aged woman-but by his opportunities to mate. But, recalling the greater variability in male reproductive success, the trajectory of a man's reproductive status may fall as well as rise through the life span. Most men start with few mating opportunities and low status. This is tolerable because they hope for the promise of later success, both at work and with women. For some, this promise is fulfilled, and their attractiveness to women may increase with their success. Thus, a man who achieves considerable success by age 45 may have more sexual opportunity than he had at 20 . In contrast to women, his reproductive status may rise until fairly late in life.

On the other hand, some men do not fare so well. Unemployment or other occupational or economic setbacks may make them less attractive to women 
and rob them of any prospect of success for the future. This points to a general developmental issue for men at this stage of life. Somewhere between 35 and 50 years of age, a man can project his trajectory of social success into the future and may estimate the probability of sustained or enhanced success. The trajectory may appear likely to level off or to begin to decline, and there may be no promise of later success or new opportunities to sustain him. Men may react to this perception in a variety of ways, with a sense of powerlessness and failure, hostility, or anger.

Of course, the balance of power in a marriage doesn't depend only on the relative reproductive status of husband and wife. Both husband and wife may either develop or fail to develop other personal or interpersonal strengths. Personality characteristics will certainly affect how negotiations are conducted.

For those men who are at least moderately successful, however, they may find that the relative reproductive status at age 45 is a reverse of what it was premaritally vis-a-vis their wives. Women have long complained that a little bit of gray hair makes a man "mature" but may make a woman only look old. Some men capitalize on this difference and leave their first wives for a younger woman. Men, at a later age than woman, may be able to have a second family in this fashion. In this sense, a sort of serial monogamy does exist in our ostensibly monogamous society. Very successful (even older) men may make a point of taking (buying, in a sense) a beautiful, much younger wife, the so-called "trophy" wife, an ornament and proof of his status and power. Of course, when a younger woman marries a much older man, she has to take into account the likelihood that he may not survive to personally invest in offspring. This suggests that such marriages will occur most often when the man is wealthy, since he may be able to "invest" after his death through his wife's inheritance of his estate.

Of course, even a middle-aged wife whose status has declined while her husband's has increased is not helpless in the negotiation of the marital quid pro quo. A patient, a depressed and anxious woman in her fifties, felt dominated by her successful husband, a banker. She was a homemaker, no longer as attractive, who had always worked hard raising the family and providing a satisfactory home life. She felt that he was having an affair and behaved as if being symptomatic was her only source of power. After being helped by antidepressant medication, she was able to sce that she needed to question the quid pro quo that she had passively complied with. Despite the affair, he had depended on her to maintain their respectable middle-class home life and their relationships with other family members. By refusing to accept this arrangement, she renegotiated a quid pro quo where he had to give up the affair.

This example illustrates a number of useful points. First, the quid pro quo is a dynamic process, subject to implicit and explicit renegotiation throughout a marriage. Second, both actual and perceived power and status are relevant. Thus, actual status will influence the number and quality of opportunities for other sexual partners or financial gain, but perceived status (about oneself) will 
limit one's ability to recognize and use effectively whatever opportunities one docs, in fact, have. As mentioned earlier, this is where individual psychological characteristics or psychopathology become relevant. In this case, the wife failed to appreciate how the initial quid pro quo (where the husband was able to have an affair) required her collaboration and cooperation. When she realized this, she found that she did have some power and was able to force a renegotiation of the marital quid pro quo. Third, although this marital negotiation does not turn directly on differences in parental investment, the nature of the role differentiation and sources of power illustrated do flow indirectly from issues of investment, changes in reproductive status, and economic control.

In view of these considerations, it may be worth speculating about their effects on recent changes in family structure that have occurred in this country. Specifically, how have the improved educational, occupational, and economic opportunities of women affected marital negotiations?

In general, these opportunities should enhance the negotiating power of women, both by making them less financially dependent on others and, perhaps, by making possible a range of alternative mating and parenting strategies. New risks may accompany these strategies, however. For example, going to college and having a career outside the home may allow women to meet potential partners not otherwise available to them. They may be free to negotiate relationships that vary from the traditional forms urged by kin. When combined with neolocal residence and effective birth control, an unprecedented degree of independence from kin (and men in general) may be possible. On the other hand, a very independent woman may lose some of the benefits that kin have to offer, such as economic support or their assistance in enforcing marital commitments or in balancing the influence of in-laws. These costs are even more significant in view of the remarkably high level of parental investment expected in even middle-class families.

This high level of expected investment means that men will still be valued for contributing to childbearing even when a woman has a career of her own. What will be the effect on the divorce rate if sufficient resources for childbearing can only be achieved with two wage earners? On one hand, this might be expected to lower the divorce rate because divorce might threaten the provision of needed resources. By contrast, one may expect higher levels of divorce and promiscuity where "the economic roles of women and men are similar, hence more easily substitutable" (Borgerhoff Mulder 1992). The direction of the effect for any particular woman will probably depend on several factors, such as the reliability of child support payments, the financial cost of divorce, the cost and availability of alternative caretakers (such as kin or day-care), and the number, quality, and accessibility of potential new partners.

If a woman earns as much or more money than her husband, she may thereby increase her power and control in marital negotiations. Hill and Hill (1990) cite a variety of evidence that when women have sources of income or support other than their husband, divorce occurs more readily. As women increase their economic strength and independence, men may utilize behaviors 
that try to re-establish their own control and dominance, such as physical abuse. Daly and Wilson (1988) have demonstrated that most spousal homicide occurs when men kill their wives because of jealousy or the wife's actual or threatened desertion. Using physical abuse to control a woman may occur at any socioeconomic level, but seems most likely to be used by men who have few other means at their disposal to establish their dominance. This will be especially true for men of low or declining status. Abuse should also occur less often in middle- and upper-class marriages since those women may find it preferable to leave the marriage rather than submit to abuse. Higher status women may find it easier to leave because of their greater economic independence, better choice of alternative mates, and probable greater ability to use the legal system to their advantage (compared to lower-class women). A woman's subjective sense of self-esteem or self-worth will affect her perception of how favorable a quid pro quo she will be able to negotiate. Note again that it is not just her actual status, but also her perception of her status and opportunities that will affect how she negotiates on her own behalf. When men find their power in a marriage decreasing because of a wife's increasing status or income, they may react with depression or anger, instead of abuse. This can hardly be surprising, given that, in our society (as in many others), the value we place on a man is likely to be closely related to his occupational status. The role of a "house husband" does not seem likely to make very many men happy.

It might he expected that marriages without children would have less conflict since parental investment is not an issue. Certainly, the absence of children removes a major source of marital conflict. However, it may still be associated with a higher divorce rate because the absence of children also removes a major motivation for reconciliation.

Finally, what is the effect of affairs on the marital balance of power? This is quite complex. In an ostensibly monogamous society, having an extramarital affair is a refusal to honor expectations of fidelity and may signal the exercise or expression of power in a marriage. The relative status of the unfaithful spouse may determine whether the infidelity is overt or covert. In the example above, the banker could be fairly casual about concealing his affairs (so that his wife knew about some of them) because he had been largely able to dictate the terms of their quid pro quo. By contrast, another patient-married to a physician-reacted to her perception of low relative power and control in the marriage by having affairs. By having affairs, she was able to feel valued by and attractive to other men, which at least temporarily decreased her depressed mood. However, because of her feeling that she had little power in the marriage, she made every effort to keep her affairs secret.

\section{FURTHER CONSIDERATIONS}

\section{In-Laws}

Conflict over investment may be especially provoked by in-laws, who may advocate strongly for the interests of kin without feeling themselves at all 
constrained by the compromises governing the husband and wife. The cultural values of the in-laws may well limit the exercise of choices that underlie negotiating strength. This may even happen to the detriment of kin. A family that opposes divorce or the independence of women may thereby rob their married daughter of a potentially strong negotiating position. (Premaritally, this may be just what the family wants if it is their goal to control who she marries.) A young couple may feel obliged to respect the wishes of in-laws either because of the need for financial support or the hope to inherit. Conflict over these matters is common and exists cross-culturally (Betzig 1989).

\section{Step-Children and Half Siblings}

The difficulties that step-children and half siblings introduce into a second marriage are common. Competition among children for parental investment-already intense among full siblings-will likely be even stronger between half siblings and greater still among step-siblings. The divergent reproductive interests of the parents will make it even more difficult to negotiate a satisfactory quid pro quo.

\section{CONCLUSION}

Although the marital therapy literature recognizes the importance of the quid pro quo in shaping the marital balance of power, it may benefit from further elaboration of the sources of marital power and the developmental changes that affect them. I have tried to show how ideas from both evolutionary theory and anthropology have something to offer in this regard. This is plainly an enormous and complex subject, and only the outlines of such an undertaking have been touched on here.

The concept of reproductive status has been emphasized because it seems either underemphasized or absent in the marital literature. It is obvious that a variety of other personal strengths and weaknesses will also affect the outcome of marital negotiations. Nevertheless, it is important to appreciate that the relative reproductive status between husband and wife may change dramatically from premarital negotiations to those of married middle age. A special problem for women is that their greatest reproductive status occurs when they are relatively immature and least advantaged economically. This, when combined with widespread values concerning the independence of women, may lead them to make poor use of that status. The shift to greater male power after marriage is consistent with the feminist perspective that marriage is a better deal for husbands than for wives (Bernard 1982).

Individual psychopathology may also have a pronounced influence on how effective a person is in these negotiations. Poor interpersonal skills, whether due to inhibitions, low self-esteem, poor understanding of social causality, negative expectations of relationships, or other cognitive and affec- 
tive limitations, will limit the person's ability to negotiate effectively. The ability to make good use of kin or other allies will also be important.

But it is a central point of this paper that the forces which have been examined-those having to do with reproductive status, parental investment, certainty of paternity, intrasexual competition, and a negotiated balance of power-will have powerful effects in even psychologically healthy individuals. These themes help shape the general landscape of marital life and the quid pro quo. Understanding them is a step toward a socioecology of marriage.

Some general implications for the treatment of individuals and couples troubled by marital conflict can be described. Some who complain of this conflict suffer from an unrealistic and historically modern expectation of marital harmony. They may he reassured, at least in part, that certain types of conflict are common, even expected, in the enormous reproductive undertaking of marriage. By looking at the reproductive problems facing men and women, one can appreciate the need for differing strategies for the sexes. This should enable the clinician to articulate unspoken assumptions about what is "proper" in married life, in terms of sex-role definition and sexual division of labor. Argument about what is "fair" may be dealt with by clear identification of the differing interests and contributions of each individual. The clinician will want to look closely at the apparent common goals of the couple, since subtle differences in terms of these goals may lead the couple to work at cross-purposes. This perspective lends a broader and more substantial theoretical footing to the use of quid pro quo in understanding negotiations between the sexes.

I would like to thank Elizabeth Hill, Randolph Nesse, Alan Lloyd. Kathryn Robine, and two anonymous reviewers for their helpful comments on this article.

\section{REFERENCES}

Alexander, R.D. Darwinism and Human Affairs, Seattle, WA: University of Washington Press, 1979 .

Bernard, J. The Future of Marriage. New Haven. CT: Yale University Press, 1982.

Betzig, L.L. Despotism and differential reproduction: a cross-cultural correlation of conflict asymmetry, hierarch, and degree of polygyny. Ethology and Sociobiology 3: 209-221, 1982.

Betzig, L.L. Causes of conjugal dissolution: a cross-cultural study. Current Anthropology 30 : $654-678,1989$.

Blumstein, P., and Schwartz, P. American Couples, New York: William Morrow, 1983.

Borgerhoff Mulder, M. Reproductive decisions. In Evolutionary Ecology and Human Behavior pp. 339-374, E.A. Smith and B. Winterhalder (Eds.). New York: Aldine de Gruyter, 1992.

Buss, D.M. Sex differences in human mate selection criteria: an evolutionary perspective. In Sociobiology and Psychology: Ideas, Issues, and Findings, C. Crawford, D. Krebs, and M. Smith (Eds.). Hillsdale, NJ: Erlbaum, 1987.

Buss, D.M. From vigilance to violence: tactics of mate retention in American undergraduates. Ethology and Sociobiology 9: 291-317, 1988.

Buss, D.M. Conflict between the sexes: strategic interference and the evocation of anger and upset. Journal of Personality and Social Psychology 56: 735-747, 1989a.

Buss, D.M. Sex differences in human mate preferences: evolutionary hypotheses tested in 37 cultures. Behavioral and Brain Sciences 12: 1-49, 1989b. 
Daly, M., and Wilson, M. Sex, Evolution, and Behavior, Boston: Willard Grant Press, 1983.

Daly, M., and Wilson, M. Homicide, New York: Aldine de Gruyter, 1988.

Daly, M., Wilson, M., and Weghorst, S.J. Male sexual jealousy. Ethology and Sociobiology 3: 11-27, 1982.

Dawkins, R., and Carlisle, T.R. Parental investment, mate desertion and a fallacy. Nature 262: 131-133, 1976.

de Waal, F. Peacemaking Among Primates, Cambridge, MA: Harvard University Press, 1989.

Elder, G.H. Appearance and education in marriage mobility. American Sociological Review 34: 519-533, 1969.

Emlen, S.T., and Oring, L.W. Ecology, sexual selection, and the evolution of mating systems. Science 197: 215-223, 1977.

Fish, R.C., and Fish, L.S. Quid pro quo revisited: the basis of marital therapy. American Journal of Orthopsychiatry 56(3): 371-384, 1986.

Flinn, M.V., and Low, B.S. Resource distribution, social competition, and mating patterns in human societies. In Ecological Aspects of Social Evolution, D.I. Rubenstein and R.W. Wrangham (Eds.). Princeton, NJ: Princeton University Press, 1986.

Foley, R.A., and Lee, P.C. Finite social space, evolutionary pathways, and reconstructing hominid behavior. Science 243: 901-906.

Glick, P.C., and Lin, S. Recent changes in divorce and remarriage. Journal of Marriage and the Family 48: 737-747, 1986.

Hill, E.M., and Hill, M.A. Gender differences in child care and work: an interdisciplinary perspective. Journal of Behavioral Economics 19(1): 81-101, 1990.

Hill, E.M., and Low, B.S. Contemporary abortion patterns: a life history approach. Ethology and Sociobiology 13: 35-48, 1992.

Jackson, D.D. Family rules: marital quid pro quo. Archives of General Psychiatry Vol. 12 589-594, 1965.

Johnson, P. Women and power: toward a theory of effectiveness. Journal of Social Issues 32: 99-110, 1976

Maynard Smith, J. Parental investment: a prospective analysis. Animal Behavior 25:1-9, 1977.

Peplau, L.A., Rubin, Z., and Hill, C.T. Sexual intimacy in dating relationships. Journal of Social Issues 33: 86-109, 1977.

Polonsky, D.C., and Nadelson, C.C. An integrative approach to couples therapy. In New Clinical Concepts in Marital Therapy, O.J. Bjorksten (Ed.). Washington, DC: American Psychiatric Association Press, 1985.

Rubenstein, D.I., and Wrangham, R.W. (Eds.). Ecological Aspects of Social Evolution, Princeton, NJ: Princeton University Press, 1986.

Stewart, T.J., Bjorksten, O.J., and Glick, I.D. Sociodemographic aspects of contemporary american marriage. In New Clinical Concepts in Marital Therapy, O.J. Bjorksten (Ed.). Washington, DC: American Psychiatric Association Press, 1985.

Symons, D. The Evolution of Human Sexuality, New York: Oxford University Press, 1979.

Trivers, R. Parental investment and sexual selection. In Sexual Selection and The Descent of Man 1871-1971, B. Campbell (Ed.). Chicago: Aldine, 1972.

Trivers, R. Social Evolution, Menlo Park: Benjamin/Cummings Publishing Co., 1985.

Washburn, S.L., and Lancaster, C.S. The evolution of hunting. In Man the Hunter, R. Lee and I. DeVore (Eds.). Chicago: Aldine, 1968.

Wilson, M., and Daly, M. Competitiveness, risk taking, and violence: the young male syndrome. Ethology and Sociobiology 6: 59-73, 1985. 